\title{
Investigation of the matrix effects on a HPLC-ESI-MS/MS method and application for monitoring triazine, phenylurea and chloroacetanilide concentrations in fresh and estuarine waters
}

\author{
N. Mazzella ${ }^{1,{ }^{*}}$, F. Delmas ${ }^{1}$, B. Delest ${ }^{1}$, B. Méchin ${ }^{1}$, C. Madigou ${ }^{1}$, J.-P. Allenou ${ }^{2}$, R. Gabellec ${ }^{2}$, \\ Th. Caquet ${ }^{3}$ \\ ${ }^{1}$ Cemagref, UR REBX, F-33612 Cestas Cedex, France \\ 2 Ifremer, Laboratoire Côtier Morbihan Pays de Loire, Nantes et La Trinité-sur-Mer, France \\ ${ }^{3}$ Inra, Équipe Écotoxicologie et Qualité des Milieux Aquatiques, Rennes, France \\ *: Corresponding author : N. Mazzella, Phone: + 335578927 18, Fax: +335 578908 01, email \\ address : Nicolas.Mazzella@bordeaux.cemagref.fr
}

\begin{abstract}
:
In this work, the effects of matrix interferences on the analytical performance of a new multiresidue method based on off-line solid phase extraction followed by reversed-phase liquid chromatographic separation and electrospray triple quadrupole mass spectrometric detection were investigated. This technique allows the simultaneous determination of 30 triazines, phenylureas and chloroacetanilides, extracted from freshwaters, in 40 minutes. Quantifications were performed with the use of appropriate internal standards (i.e. atrazine D5, diuron D6 and metolachlor D6). The limits of quantification were from 1 to $32 \mathrm{ng} \mathrm{L}^{-1}$ for the triazines, from 5 to $59 \mathrm{ng} \mathrm{L}^{-1}$ for the phenylureas and from 13 to $54 \mathrm{ng} \mathrm{L}^{-1}$ for the chloroacetanilides. The matrix effects were studied by spiking various waters (i.e. tap, river, pond and sea waters) with the chemicals of interest. The results showed that the samples with the highest conductivity (i.e. seawater) and the most abundant dissolved organic matter content (i.e. pond water) exhibited important matrix effects with signal suppressions and high imprecision, respectively. These matrix effects were strongly minimized by performing appropriate internal standardizations. Afterward, this analytical method was applied for analyzing environmental samples from either river or estuarine waters and for monitoring herbicide input in a freshwater-seawater interface.
\end{abstract}

Keywords: HPLC-ESI-MS/MS, multiresidue method, matrix effects, herbicides, natural water quality, river-estuarine interface 


\section{Introduction}

(2)

(n)

Herbicides are representative of $40-45 \%$ of the agricultural pesticide use in the world $^{1}$. Regarding the herbicide legislation, there are some differences between US and European policies. For instance, the phenylureas are not used at all in US whereas several triazines and phenylureas are controlled or even forbidden in Europe. This is the case of the atrazine since it was completely banned from the agricultural use in many countries (e.g. Germany, Italy, Austria, Sweden, Norway and France). However, several triazines and phenylureas are authorized for the non-agricultural purposes which represent $22 \%$ of the total herbicide use ${ }^{1}$. The European framework directive in the field of water policy 2000/60/EC ${ }^{2}$ seek to prevent deterioration, to enhance and to restore bodies of surface water, to achieve good chemical and ecological status of such water and to reduce pollution from discharges and emissions of hazardous substances. Among these hazardous substances, the monitoring of herbicides such as atrazine, simazine, alachlor, diuron and isoproturon in freshwaters is imperative and there is a need for pertinent and accurate data to compare with current legislation and environmental quality standards ${ }^{3}$. Regarding to drinking water, the levels of the pesticide residues in natural waters is of public concern and the maximum concentration admissible for pesticides is $0.1 \mu \mathrm{g} \mathrm{L} \mathrm{L}^{-1}$ for individual compounds and $0.5 \mu \mathrm{g} \mathrm{\textrm {L } ^ { - 1 }}$ for the sum of them ${ }^{4}$.

Several methods were developed for the simultaneous analysis of different herbicide classes. Multiresidue methods using GC/MS can be applied for the analysis of triazines ${ }^{5,6}$ and chloroacetanilides ${ }^{6,7}$ but the determination of thermally labile phenylureas is more delicate since the degradation products depend on the injection solvent composition ${ }^{8}$. Classical approaches are based on on-line or off-line solid-liquid extractions followed by HPLC-DAD analyses ${ }^{9-12}$ but UV detection lack of specificity and both identifications and 
83

quantifications can be difficult with complex matrices. More recent multiresidue methods involved HPLC separations coupled with electrospray mass spectrometric (ESI-MS) detections 10, 11, 13-20. This technique allows the simultaneous determination of several herbicides with short analysis times but the purity of the samples must be considered. In fact, the response with electrospray ionization is affected by the polar/ionisable impurities which may be present in the matrix and perturb the ionization processes ${ }^{21,22}$.

This paper addresses two objectives with the investigation of the matrix effects for various types of water samples and the development of an accurate method based on ESIMS/MS detection that will be used for monitoring several herbicides in these types of waters. This method consists in an improvement of a previous HPLC-DAD multiresidue technique based on an off-line solid phase extraction of several polar herbicides from freshwaters ${ }^{9,23}$. The use of the ESI-MS/MS detection allowed the quantification of a larger number of compounds with a shorter analysis time. Nevertheless, a correction of the signal suppression (or enhancement) due to the matrix effects was necessary. Thus, the matrix effects were studied by spiking different natural waters with various conductivities and low or high dissolved organic matter contents as impurities. Afterwards, this multiresidue method was applied for monitoring herbicide concentrations in rivers and in a freshwater-seawater estuarine interface. 


\section{Experimental}

104

\section{Chemicals}

106

Acetonitrile supragradient, methanol gradient and water gradient (HPLC grade) were purchased from ICS-SCIENCE Groupe (France). Oasis HLB cartridges (6 mL, 500 mg, 60 $\mu \mathrm{m})$ were provided by Waters (France). GF/F filters (47 $\mathrm{mm} \varnothing$ ) were provided by Whatman (France). All analytical standards were purchased from Dr. Ehrenstorfer (Germany): ametryn, atrazine, cyanazine, atrazine-desethyl (DEA), terbuthylazine-desethyl (DET), atrazine112 desisopropyl (DIA), irgarol 1051, prometryn, propazine, simazine, terbuthylazine, terbutryn, 113 chlortoluron, diuron, 1-(3,4-dichlorophenyl)-3-methylurea (DCPMU), 1-(3,4-dichlorophenyl)-

114 urea (DCPU), fenuron, isoproturon, 1-(4-isopropylphenyl)-3-methylurea (IPPMU), 1-(4isopropylphenyl)-urea (IPPU), linuron, metobromuron, metoxuron, monolinuron, monuron, neburon, acetochlor, alachlor, metolachlor, metazachlor, atrazine D5, DEA D6, diuron D6, 117 metolachlor D6 and prometryn D6.

\section{Solid phase extractions}

Preconcentration of the analytes from water samples was accomplished by using solid-

122 phase extraction (SPE) with Oasis HLB cartridges. This SPE procedure is adapted from 123 previous works ${ }^{9,23}$. Prior to SPE, $200 \mathrm{~mL}$ of water samples (pH adjusted to 7) were filtered 124 using GF/F glass microfibre filters $(0.7 \mu \mathrm{m}$ pore size) and $10 \mu \mathrm{L}$ of a stock solution 125 (acetonitrile) containing $10 \mathrm{ng} \mathrm{LL}^{-1}$ of atrazine D5, diuron D6 and metolachlor D6 was added, 126 resulting in fortification of the water samples with $0.5 \mu \mathrm{g} \mathrm{L} \mathrm{L}^{-1}$ of each internal standard. SPE 127 was conducted using a VisiPrep 12-port manifold (Supelco, France). The conditioning, 
extraction and rinsing steps were carried out under a 400 mm Hg vacuum (1 mmHg=133.322 Pa). The SPE cartridges were successively washed with $10 \mathrm{~mL}$ of methanol, conditioned with $10 \mathrm{~mL}$ of HPLC grade water, loaded with $200-\mathrm{mL}$ water samples, then rinsed with $20 \mathrm{~mL}$ of HPLC grade water and dried with a stream of nitrogen for 30 minutes. Elutions were achieved with $5 \mathrm{~mL}$ of methanol. The 5-mL extracts were blown under a gentle stream of nitrogen and dissolved in $1 \mathrm{~mL}$ of an acetonitrile:water (10:90, v/v) mixture prior to the HPLC-ESIMS/MS analyses. The final concentrations of the surrogates were about $100 \mu \mathrm{g} \mathrm{L}^{-1}$ after the solid phase extraction.

\section{Evaluation of matrix effects}

River and pond waters were collected in southwest part of France (Anan and Cestas, respectively). Seawater samples were collected in the Vilaine estuary, Brittany, France (Figure 1). Postextraction standard additions were performed for the evaluation of the matrix effects (Table 1) ${ }^{24}$. For this purpose, $3 \times 200 \mathrm{~mL}$ of non fortified matrices (either tap, river, pond or sea water) were conditioned, filtered and preconcentrated using SPE as described previously. All the extracts were dried with nitrogen, spiked with $100 \mu \mathrm{g} \mathrm{L}^{-1}$ of both test chemicals and internal standards and then dissolved in $1 \mathrm{~mL}$ of an acetonitrile:water (10:90, v/v) mixture. In addition, one blank extraction of each matrix was done. Each blank was fortified with internal standards only and analyzed separately to determine the background concentrations.

\section{Dissolved organic carbon measurements}


153 The water samples were filtered using GF/F glass microfibre filters ( $0.7 \mu$ m pore size $)$ and the 154 concentrations of DOC were measured using a model 1010 OI Analytical carbon analyzer 155 with a 1051 auto-sampler (Bioritech, France). The total organic carbon analyses were 156 performed with an high-temperature persulfate oxidation technology and according to the 157 European standard ISO 8245:1999 ${ }^{25}$.

158

159

160

161

162

163

164

165

166

167

168

169

170

171

172

173

174

175

176

\section{HPLC separation}

HPLC system: Finnigan SpectraSYSTEM SCM1000 Solvent Degasser, Finnigan SpectraSYSTEM P4000 Quaternary Pump, Finnigan SpectraSYSTEM AS3000 Autosampler (column oven set at $40^{\circ} \mathrm{C}$ ) and Finnigan UV6000LP photodiode array detector (Thermo Electron Corporation, MA, USA). Detection wavelengths: $\lambda=220 \mathrm{~nm}$ for ametryn, atrazine, cyanazine, DEA, DET, DIA, irgarol 1051, prometryn, propazine, simazine, terbuthylazine, terbutryn, acetochlor, alachlor, metolachlor and metazachlor, $\lambda=240 \mathrm{~nm}$ for chlortoluron, diuron, DCPMU, DCPU, fenuron, isoproturon, IPPMU, IPPU, linuron, metobromuron, metoxuron, monolinuron, monuron, and neburon. The HPLC separation of triazines, phenylureas and chloroacetanilides (Figure 2) was performed with a Prontosil Spheribond ODS 2 column $(150 \times 4 \mathrm{~mm}, 3 \mu \mathrm{m})$ with a $\mathrm{C}_{18}(10 \times 4 \mathrm{~mm}, 6 \mu \mathrm{m})$ guard column (Bischoff Chromatography, Germany). The injection volume and solvent composition were $50 \mu \mathrm{L}$ and acetonitrile:water (10:90, v/v), respectively. The corresponding binary gradient composition is given in Table 3.

\section{ESI-MS/MS detection}


178 France) triple quadrupole mass spectrometer equipped with a turboionspray source (ESI).

179 Optimization of source, gas and compound dependent parameters were achieved by infusing 180 pure standard solutions (1 $\mathrm{mg} \mathrm{L}^{-1}$ in acetonitrile:water mixtures) into the turboionspray source 181 at a flow rate of $10 \mu \mathrm{L} \min ^{-1}$ by using a syringe pump. The ionization mode was positive, the 182 ion spray voltage was held at $+5500 \mathrm{~V}$ and the declustering potential was optimized for each

183

184 compound with voltages of about 20-30 V. The electron multiplier was set up to $2400 \mathrm{~V}$. The nebulizing gas CG1 $\left(\mathrm{N}_{2}\right)$, the drying-gas CG2 $\left(\mathrm{N}_{2}\right)$ and the curtain gas $\left(\mathrm{N}_{2}\right)$ pressures were 45 psi, 80 psi and 40 psi, respectively. The CG2 temperature was set up to $500^{\circ} \mathrm{C}$. CID production spectra were acquired by colliding the Q1 selected precursor ions with $\mathrm{N}_{2}(\mathrm{CAD}=3 \mathrm{psi})$ and applying collision energies from 25 to $40 \mathrm{~V}$ in Q2. Both Q1 and Q3 were operated at unit resolution and the step size was $\mathrm{m} / \mathrm{z}=0.1$. The optimal multiple reaction monitoring (MRM) quantitative transitions of both test chemicals and internal standards are reported in Table 4. The parent ions of the MRM transitions correspond to the $[\mathrm{M}+\mathrm{H}]^{+}$molecular peaks. Dwell times of 50 ms were used for each triazine or phenylurea whereas dwell times of 100 ms were used for each chloroacetanilide. A total dwell time of 1,9 s was used, resulting in a minimum of 12 data points for every chromatographic peak. Both external and internal calibration procedures were performed and the concentration ranges for the calibration curves were from

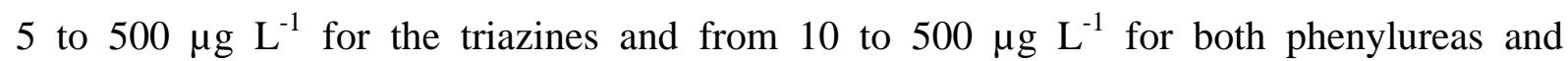
chloroacetanilides. $100 \mu \mathrm{g} \mathrm{L}{ }^{-1}$ solutions of atrazine D5, diuron D6 and metolachlor D6 were used for the respective internal quantifications of triazines and their metabolites, phenylureas and their metabolites, and chloroacetanilides. 


\section{Results and discussion}

203

204

205

206

207

208

209

210

211

212

213

\section{Matrix spike experiments}

It is well known that electrospray ionization suffers from matrix effects when polar/ionic compounds other than the analytes of interest, such as those originating from the sample matrix, are present ${ }^{21,22}$. This phenomenon is attributed to competitive ionization of all of the appropriate species present in the sample ${ }^{26}$. The matrix effects may induce a loss of sensibility (i.e. ion suppression) and may well affect both accuracy and precision. Different methods can be used for overcoming the matrix effects: the complete removal of co-eluting substances by sample clean-up techniques such as gel permeation chromatography or solid phase extraction ${ }^{16}$. Such an approach is time consuming and difficult if the matrix is complex. Alternatively, the calibration standards can be make up in a matrix extract rather than in a pure solvent ${ }^{19,27}$. The problem with this method is that the composition of such an extract cannot be guaranteed to be identical to that in which the chemical of interest must be determined ${ }^{22}$. Another common approach is based on the standard additions. Such a method provides both good accuracy and precision but the main disadvantage is that further analyses must be performed. Therefore, this approach is not suitable for daily and extensive analyses.

Lastly, the use of internal standards would improve both accuracy and precision ${ }^{17,18,27}$, but appropriate internal standards are sometimes not available. Concerning this work, different water matrices were spiked with the chemicals of interest for estimating the matrix effects. Some internal standards representative of three different herbicide classes (i.e. triazines, phenylureas and chloroacetanilides) were selected. Both internal and external calibrations were done and compared. 
Triplicates of unfortified tap, river, pond and sea waters were preconcentrated using

SPE. The matrices were spiked with both test chemicals and internal standards after solid phase extractions in order to eliminate the variability of the SPE recoveries and to estimate the matrix effects only. The seawater matrix analysis showed background concentrations lower than the limits of detection (LODs) for every compound. The analysis of the blank river matrix revealed background concentrations lower than the limits of quantification (LOQs; Table 4) for atrazine, DEA and simazine, and lower than the LODs for the other chemicals of interest. The analysis of the blank pond matrix showed background concentrations lower than the LOQs for diuron, fenuron, isoproturon and monuron, and lower than the LODs for the other chemicals of interest. Consequently, for each matrix, the contribution of the background concentrations was negligible (lower than 1 and $5 \mu \mathrm{g} \mathrm{L}^{-1}$ for the triazines and the phenylureas, respectively) in comparison to the concentrations of the fortifications $\left(100 \mu \mathrm{g} \mathrm{L}^{-1}\right)$. The Table 1 gives the concentrations calculated with either external calibrations or internal calibrations. The spiking of tap and river waters with the test chemicals showed no significant differences between the internal and external calibrations (Table 1). There were also no peculiar matrix effects since the mean values of the triplicates were contained between 88 and $119 \%$ of deviation (85-115 \% for the internal calibrations). For the two matrices, the relative deviations from the expected $100 \mu \mathrm{g} \mathrm{L}{ }^{-1}$ may be attributed to the instrumental uncertainty.

The HPLC-DAD analysis of both river and pond matrices spiked with the test chemicals may indicate the higher abundance of UV-absorbing organic matter in the pond water (Figure 2 a). The results of the dissolved organic carbon analysis (Table 2) confirmed this assumption with values of about 92 and $1.7 \mathrm{mg} \mathrm{L}^{-1}$ for the pond and river waters, respectively. Thus, the SPE purification did not eliminate all the dissolved organic matter (DOM) and regarding to the pond matrix, the concentrations were slightly overestimated with the external calibration (Table 1), especially for phenylureas and chloroacetanilides with 
251 relative deviations between 106 and $128 \%$ (except fenuron with $98 \%$ ). Steen et al. ${ }^{28}$

252 observed some matrix effects such as ion suppression with the presence of DOM like humic 253 acids. The authors performed external calibration and suggested the use of a tandem 254 aminopropyl/LiChrolut EN SPE set-up for removing the humic acids. In our case, the SPE 255 procedure was not modified for the pond matrix and the use of surrogates such as diuron D6 256 and metolachlor D6 minimized the matrix effects for phenylureas and chloroacetanilides, 257 respectively. Actually, relative deviations of 100-114 \% for both classes with the internal 258 calibration (except DCPMU and fenuron with 120 and $92 \%$, respectively) were observed. For 259 the triazines, the use of DEA D6 instead of atrazine D5 as internal standard for both DIA and 260 DEA did not provide significant improvements of the results. Prometryn D6 was also tested 261 for the quantification of the methylthiotriazines (i.e. irgarol 1051, prometryn, ametryn and 262 terbutryn). The correction of the matrix effects was slightly better for some compounds (e.g. $263112 \%$ instead of $121 \%$ for terbutryn) but the occurrence of non-deuterated prometryn (about 264 $1 \%$ of the internal standard as impurity) could be problematic for the measurement of this herbicide at trace level. Furthermore, the interfering DOM present in the pond sample matrix 266 induced higher imprecision with the external calibrations than with the internal calibrations. 267 For instance, with the external calibration, relative standard deviations were higher than $25 \%$ 268 for 11 compounds and the respective RSDs of some herbicides like cyanazine and IPPU were 269 up to $43 \%$. Regarding to the internal calibration method, the RSDs were mostly $\leq 10 \%$ and 270 the highest value was observed for IPPU (24\%). Therefore, methods based on standard 271 addition into such a matrix without internal standard corrections might result in imprecise 272 quantifications.

The seawater matrix is characterized by a low DOC content and the highest conductivity (Table 2). Like the river water, the HPLC-DAD analysis of the seawater (not 275 showed) revealed the low abundance of UV-adsorbing interfering compounds. The HPLC- 
ESI-MS/MS analysis (Table 1) showed strong ion suppression effects for some triazines like atrazine (62 \%), DEA (61 \%), DET (59 \%), simazine (52 \%) and terbuthylazine (66 \%) when only external standardizations were performed. Signal suppression or enhancement was reported by Gil-García et al. ${ }^{29}$ concerning the ESI analysis of some pyrethroids in seawater. The authors attributed these matrix effects to the presence of salts and others ionic compounds in the ionization source and suggested a cleanup step during the SPE procedure. In our study, the use of appropriate surrogates clearly reduced the matrix effects since values from $82 \%$ (simazine) to $116 \%$ of deviation (DIA and the metoxuron) were observed. Lastly, the RSDs were slightly better and acceptable with the use of internal standards ( $\leq 22 \%)$.

Finally, it seems that internal standardization is necessary for a matrix with high DOM content (i.e. pond water) for a better precision. This approach is also useful and sufficient for improving the accuracy with some peculiar matrices (i.e. sea water).

\section{HPLC-ESI-MS/MS multi-residue analysis and SPE recoveries}

The SPE optimized recoveries obtained with tap waters fortified with either $0.1 \mu \mathrm{g} \mathrm{L}{ }^{-1}$ $(n=5)$ or $0.5 \mu g \mathrm{~L}^{-1}(\mathrm{n}=10)$ of test chemicals are reported in Table 4 . The lowest values were observed for DEA and metazachlor with $73 \%$, fenuron and metobromuron with $75 \%$, and simazine with $78 \%$. For all the other herbicides, recoveries were $\geq 80 \%$. As shown before, the matrix effects are low for the tap water, especially with the use of surrogates. Consequently, these values really correspond to the SPE recoveries and they are in good agreement with the previous results obtained by Carabias-Martínez et al. ${ }^{11}$ for extracting neutral phenylureas and acidic sulfonylureas. Different volumes of methanol were used for the elution and there was no real improvement of the results over $5 \mathrm{~mL}$ of solvent ${ }^{23}$. The extractions carried out with the Oasis HLB cartridges showed good reproducibility for most of 
301 the test chemicals (RSD $\leq 18 \%$ ). Only DET exhibited a really higher RSD (22 \%).

302 Reproducibility of the SPE-HPLC-MS/MS method was carried out with the measurement of 303 the same material (tap water spiked at two different levels, Table 4) under changed conditions 304 of time (1 week between each extraction and analysis) and with different observers.

305 The limits of quantification (Table 4) and the limits of detection were determined by 306 diluting standard solutions until ratios of $\mathrm{S} / \mathrm{N}=10$ and $\mathrm{S} / \mathrm{N}=3$, respectively. The 307 chromatographic separation of the 30 test chemicals in 40 minutes is shown in Figure 2. 308 Carry-over effects were not observed with the ESI-MS/MS detection. The linear dynamic 309 ranges were from the LOQ to $500 \mu \mathrm{g} \mathrm{L}^{-1}$. A replicate analysis $(\mathrm{n}=4)$ of the same sample $(100$

$310 \mu \mathrm{g} \mathrm{L^{-1 }}$ standard solution in an acetonitrile:water mixture) was performed and the relative 311 standard deviations (RSDs) of the ESI-MS/MS detection were $\leq 12 \%$ for triazines, $\leq 10 \%$ 312 for phenylureas and $\leq 9 \%$ for chloroacetanilides.

\section{Solid phase extraction and HPLC-ESI-MS/MS analysis of fortified river water samples}

The results related to the spiking of river water with the test chemicals are reported in Table 4. The samples were fortified at two different level concentrations $(0.05$ and $0.5 \mu \mathrm{g} \mathrm{L}$

${ }^{1}$ ), preconcentrated by using the SPE procedure and quantified with internal calibrations. The data did not require corrections for the background concentrations as mentioned above. The results showed that the relative deviations from the expected values were higher but 321 acceptable for the lowest concentration. In fact, most of the deviations did not exceed $\pm 30 \%$ except for cyanazine, DEA and metazachlor (about $+40 \%$ with 69-70 ng $\mathrm{L}^{-1}$ ). The relative 323 deviations became negligible at higher concentrations with values from $0.393 \mu \mathrm{g} \mathrm{L}{ }^{-1}$ (IPPU) 324 to $0.641 \mu \mathrm{g} \mathrm{L}^{-1}$ (prometryn). Globally, the data showed that this multiresidue HPLC-ESI- 
MS/MS method based on internal calibrations provides reliable quantitative results for river 326 waters.

\section{Application to the waters from the Vilaine river and estuary}

Several water samples from the Vilaine river and estuary were collected between April $33116^{\text {th }}$ to June $12^{\text {th }} 2007$. As shown in Figure 1 , the sampling sites were located in the river upstream (Arzal dam) and in the estuary (les Granges and Maresclé). The samples from the Arzal dam correspond to the freshwaters coming from the Vilaine river and the samples from les Granges and Maresclé are characteristic of a marine environment. The estuarine waters were collected at either low tide or high tide. During april $16^{\text {th }}$, the sample from Arzal contained only some traces of DEA $\left(0.03 \mu \mathrm{g} \mathrm{L}^{-1}\right)$, diuron $\left(0.05 \mu \mathrm{g} \mathrm{L}^{-1}\right)$, and isoproturon $(0.12$

$\mu \mathrm{g} \mathrm{L}^{-1}$ ) (Figure 3). Isoproturon is generally used for the winter wheat weeding. The analyses lower than the LOQs.

On May $29^{\text {th }}$, the freshwater from Arzal showed concentrations of diuron and

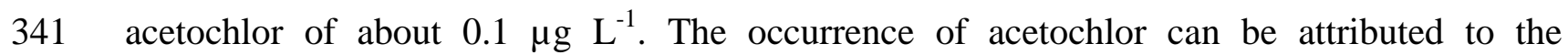
342 agricultural treatments during the spring. Diuron is forbidden for the agricultural purposes in 343 Brittany. However this compound is used as biocide in the antifouling paints ${ }^{30}$ and its 344 occurrence is probably due to the high sailing activity at the Arzal dam. At the same date, the 345 analysis of the sample from Les Granges at low water revealed the occurrence of atrazine, 346 DEA, simazine, diuron, isoproturon and acetochlor whereas the Maresclé (sample colleted 347 during the low water as well) was less impacted by these chemicals (detection of metolachlor 348 only). The sampling site of Les Granges is closer to the Arzal dam and, consequently, it 349 should be more contaminated by the herbicides carried out by the freshwaters from the river. 
Finally, strong dilutions (concentrations < LOQs) were observed for both Les Granges and

351 Maresclé about 6 hours later (samples collected during the high tide).

352

The last sample (June $12^{\text {th }}$ ) from Arzal exhibited an increase of irgarol 1051 and 353 diuron concentrations $\left(0.19 \mu \mathrm{g} \mathrm{L}^{-1}\right.$ and $0.24 \mu \mathrm{g} \mathrm{L}{ }^{-1}$, respectively). Both of these chemicals are 354 contained in antifouling paints ${ }^{30-32}$. Some chloroacetanilides (alachlor, acetochlor and 355 metolachlor) were detected but their concentrations did not exceed $0.1 \mu \mathrm{g} \mathrm{L}^{-1}$. Regarding to 356 current environmental quality standards (EQS) ${ }^{3}$ applicable to surface and coastal water ${ }^{33}$, the 357 relatively short period of the study (3 sampling campaigns in two months) makes the comparison with the annual average (AA) EQS difficult. Only the concentration of the diuron on June $12^{\text {th }}$ exceeded the AA-EQS with $0.24 \mu \mathrm{g} \mathrm{L}{ }^{-1}$ (Arzal dam) but this value was really 360 lower than the maximum allowable concentration (MAC) EQS (1.8 $\left.\mu \mathrm{g} \mathrm{L}^{-1}\right)$. Consequently, if 361 only the results obtained during the couple of months are considered, it might be assumed that 362 the chemical pollution should not disturb the aquatic ecosystems of both Vilaine river and Arzal dam for this period. Our results showed also an input of several herbicides in the estuary but, at our knowledge, there are no legislative limits for some pollutants (i.e. irgarol 1051, acetochlor and metolachlor) in coastal water. Unlike to the results obtained on May $29^{\text {th }}$, very low concentrations were detected in the marine environment at both low and high waters (only some traces of diuron and simazine in Les Granges) on June $12^{\text {th }}$ (Figure 3). This decrease might be attributed to a lower contribution of freshwaters since the weekly average flow rates of the Vilaine river at the Arzal dam were about $70.6 \mathrm{~m}^{3} \cdot \mathrm{s}^{-1}$ and $44.7 \mathrm{~m}^{3} \cdot \mathrm{s}^{-1}$ before May $29^{\text {th }}$ and June $12^{\text {th }}$, respectively.

371 However, the daily amount estimates of some herbicides like diuron and irgarol 1051 were 372 higher on June $12^{\text {th }}$ (770 $\mathrm{g}$ and $610 \mathrm{~g}$, respectively) than on may $29^{\text {th }}$ (520 $\mathrm{g}$ and non-detected, 373 respectively). In the same way, the large daily amount of isoproturon (570 g) carried by the 374 Vilaine river on April $16^{\text {th }}$ was not revealed within the estuarine waters. Thus, it appears that 
375 hydrometric data associated to a grab sampling may not explain the behaviour of the 376 herbicides in this estuary. Such a hydrosystem is characterized by strong dilution and 377 dispersion phenomena due to the tides. In this case, grab samples give only a snapshot of the 378 water contamination level and more reliable concentration estimates could be achieved with

379 the use of polar organic chemical integrative samplers ${ }^{23,}{ }^{34}$. Actually, such devices allow the 380 determination of time-weighted average (TWA) concentrations, which is a fundamental part 381 of an ecological risk assessment process for chemical stressors and the further determination 382 of EQS for marine waters.

\section{Acknowledgments}

Financial support was provided by the “Agence Nationale de la Recherche” within the

387 framework of the program "ECosphère COntinentale" coordinated by the "Institut des 388 Sciences de l'Univers" of the CNRS. The authors would like to thank M. Bonnet, M. 389 Boudigues and J. Granges for their skilful technical assistance. 
393 Table 1. Determination of the matrix effects with $200 \mathrm{~mL}$ of various waters $(\mathrm{n}=3$ for each

394 matrix) preconcentrated by using SPE and then spiked with $100 \mu \mathrm{g} \mathrm{L}^{-1}$ of the test chemicals

395 (triplicates). Values expressed in \% of deviation from the expected concentrations (\% RSD).

396

\begin{tabular}{|c|c|c|c|c|c|c|c|c|}
\hline \multirow{2}{*}{ Herbicides } & \multicolumn{2}{|c|}{ Tap water } & \multicolumn{2}{|c|}{ River water } & \multicolumn{2}{|c|}{ Pond water } & \multicolumn{2}{|c|}{ Sea water } \\
\hline & E.S. $^{a}$ & I.S. $^{a}$ & E.S. & I.S. & E.S. & I.S. & E.S. & I.S. \\
\hline Ametryn & $103(5)$ & $99(2)$ & $100(9)$ & $108(6)$ & $99(6)$ & 104 (15) & 89 (5) & 105 (15) \\
\hline Atrazine & $108(4)$ & $100(8)$ & $93(6)$ & $100(5)$ & 104 (24) & 107 (1) & $62(8)$ & $96(2)$ \\
\hline Cyanazine & $88(18)$ & $91(8)$ & 103 (3) & $111(4)$ & $126(43)$ & $124(11)$ & 104 (17) & 115 (9) \\
\hline DEA & $98(1)$ & 91 (3) & 99 (4) & $106(8)$ & $90(28)$ & 91 (8) & $61(6)$ & 99 (3) \\
\hline DET & $93(6)$ & $85(8)$ & $95(8)$ & $103(6)$ & $103(30)$ & $105(5)$ & $59(8)$ & $99(1)$ \\
\hline DIA & $94(6)$ & $88(4)$ & $90(14)$ & $96(18)$ & 88 (34) & 88 (13) & $83(10)$ & $116(4)$ \\
\hline Irgarol 1051 & $100(7)$ & $92(9)$ & $94(6)$ & $102(5)$ & $118(8)$ & $119(16)$ & 94 (10) & 112 (15) \\
\hline Prometryn & $101(4)$ & $98(3)$ & $101(9)$ & $109(7)$ & $108(7)$ & 112 (16) & $93(4)$ & 104 (18) \\
\hline Propazine & $98(1)$ & $93(7)$ & $90(9)$ & $96(9)$ & $124(32)$ & $122(9)$ & $66(10)$ & $103(2)$ \\
\hline Simazine & $103(9)$ & $96(12)$ & $96(6)$ & $105(4)$ & $98(20)$ & $101(5)$ & $52(5)$ & $82(2)$ \\
\hline Terbuthylazine & 97 (5) & 89 (9) & $90(11)$ & $97(11)$ & 112 (25) & $119(8)$ & $66(11)$ & 102 (5) \\
\hline Terbutryn & 98 (8) & $94(5)$ & $95(6)$ & $103(4)$ & $116(13)$ & $121(13)$ & $92(6)$ & $101(20)$ \\
\hline Chlortoluron & $102(6)$ & 97 (6) & $96(1)$ & $101(5)$ & 119 (25) & $111(10)$ & 104 (12) & 113 (9) \\
\hline Diuron & $110(13)$ & 104 (13) & $101(2)$ & $106(5)$ & $126(17)$ & $112(5)$ & $86(12)$ & $103(5)$ \\
\hline DCPMU & 119 (3) & $113(4)$ & $92(7)$ & 97 (6) & $128(20)$ & $120(8)$ & 89 (9) & 106 (9) \\
\hline DCPU & 92 (13) & 94 (11) & $93(2)$ & $98(3)$ & 124 (39) & $114(20)$ & 78 (13) & $96(3)$ \\
\hline Fenuron & $103(6)$ & $98(6)$ & $91(8)$ & $95(12)$ & $98(22)$ & $92(9)$ & $103(4)$ & $107(22)$ \\
\hline Isoproturon & $111(6)$ & $104(6)$ & $93(4)$ & 97 (6) & 114 (22) & $108(8)$ & $123(7)$ & 113 (17) \\
\hline IPPMU & $105(9)$ & $100(9)$ & $95(1)$ & 99 (5) & 117 (30) & $110(13)$ & 102 (13) & $114(10)$ \\
\hline IPPU & 105 (18) & $100(11)$ & $100(5)$ & $104(1)$ & $122(43)$ & $113(24)$ & 97 (18) & $111(7)$ \\
\hline Linuron & 115 (11) & 109 (11) & $106(2)$ & $111(6)$ & $108(11)$ & $103(7)$ & 82 (25) & $101(15)$ \\
\hline Metobromuron & $106(5)$ & $100(5)$ & 99 (6) & $102(4)$ & $111(16)$ & $105(6)$ & 89 (19) & 108 (13) \\
\hline Metoxuron & $118(11)$ & $112(11)$ & $96(1)$ & $101(2)$ & $118(26)$ & 107 (14) & $111(10)$ & $116(14)$ \\
\hline Monolinuron & $92(7)$ & $89(4)$ & 107 (7) & $111(5)$ & $106(17)$ & $100(1)$ & $86(10)$ & 105 (11) \\
\hline Monuron & 96 (12) & 92 (12) & $91(4)$ & $107(1)$ & 111 (17) & $104(11)$ & $106(12)$ & 113 (9) \\
\hline Neburon & 109 (16) & $102(14)$ & $94(2)$ & 99 (6) & 115 (22) & $109(6)$ & $91(9)$ & 109 (14) \\
\hline Acetochlor & $114(12)$ & $104(8)$ & $89(5)$ & $101(7)$ & 122 (15) & $106(2)$ & $92(21)$ & $89(6)$ \\
\hline Alachlor & $96(2)$ & 90 (13) & 95 (3) & $106(7)$ & 117 (12) & $101(6)$ & 79 (12) & 82 (12) \\
\hline Metolachlor & $105(12)$ & $95(6)$ & $92(1)$ & $104(6)$ & $115(21)$ & $100(4)$ & $108(30)$ & $106(9)$ \\
\hline Metazachlor & $116(5)$ & 109 (10) & $106(4)$ & $115(9)$ & $122(24)$ & $104(5)$ & 109 (26) & $110(11)$ \\
\hline
\end{tabular}

397

$398{ }^{\mathrm{a}}$ Quantifications with either external (E.S.) or internal (I.S.) standardizations.

399 
401 Table 2. Physicochemical properties of the different matrices.

402

\begin{tabular}{ccccc}
\hline Parameters & Tap water & River water & Pond water & Sea water \\
\hline Conductivity $\left(\mu \mathrm{S} \mathrm{cm}^{-1}\right)$ & 423 & 199 & 228 & 53300 \\
$\mathrm{pH}$ & 7.35 & 7.67 & 6.63 & 7.81 \\
DOC $\left(\mathrm{mg} \mathrm{L}^{-1}\right)^{\mathrm{a}}$ & $0.45 \pm 0.01$ & $1.69 \pm 0.03$ & $92.35 \pm 4.23$ & $1.30 \pm 0.04$ \\
\hline
\end{tabular}

403

404

${ }^{\text {a }}$ Values \pm 1 S.D.

405

406

407 Table 3. Linear gradient composition (A: acetonitrile, B: water) for the separation of triazines, 408 phenylureas and chloroacetanilides on a reversed-phase column (Spheribond ODS 2, 150 x 4 $409 \mathrm{~mm}, 3 \mu \mathrm{m})$.

410

411

\begin{tabular}{cccc}
\hline Time $(\mathrm{min})$ & $\% \mathrm{~A}$ & $\% \mathrm{~B}$ & Flow rate $\left.(\mathrm{mL} \mathrm{min})^{-1}\right)$ \\
\hline 0 & 10 & 90 & 0.5 \\
2 & 10 & 90 & 0.5 \\
18 & 45 & 55 & 0.5 \\
30 & 80 & 20 & 0.6 \\
33 & 80 & 20 & 0.6 \\
36 & 10 & 90 & 0.5 \\
40 & 10 & 90 & 0.5 \\
\hline
\end{tabular}

412

413 
414 Table 4. LC-ESI-MS/MS and SPE optimized parameters for the herbicide analysis (2 level 415 fortification of tap water). Validation of the method with the fortification of a river water with 416 either 0.05 or $0.5 \mu g \mathrm{~L}^{-1}$.

\begin{tabular}{|c|c|c|c|c|c|c|c|}
\hline $\begin{array}{c}\text { Peak } \\
\text { numbers }\end{array}$ & Herbicides & $\begin{array}{c}\text { MRM } \\
\text { transitions }\end{array}$ & Surrogates & $\begin{array}{c}\text { Recoveries }^{\text {a }} \\
\text { (\% RSD) }\end{array}$ & $\begin{array}{l}\mathrm{LOQ}^{\mathrm{b}} \\
\left(\mathrm{ng} \mathrm{L}^{-1}\right)\end{array}$ & $\begin{array}{l}\text { River water }{ }^{\mathrm{C}} \\
\text { spiked with } \\
50 \mathrm{ng} \mathrm{L}^{-1} \\
\end{array}$ & $\begin{array}{c}\text { River water }{ }^{c} \text { sike }^{\text {spiked with }} \\
500 \text { L L }^{-1}\end{array}$ \\
\hline 1 & Ametryn & $228>186$ & Atrazine D5 (221>179) & 96 (13) & 1 & 58 & 586 \\
\hline 2 & Atrazine & $216>174$ & Atrazine D5 & $96(12)$ & 3 & 52 & 525 \\
\hline 3 & Cyanazine & $241>214$ & Atrazine D5 & $104(11)$ & 23 & 69 & 436 \\
\hline 4 & DEA & $188>146$ & Atrazine D5 & $73(14)$ & 7 & 69 & 585 \\
\hline 5 & DET & $202>146$ & Atrazine D5 & $105(22)$ & 3 & 52 & 427 \\
\hline 6 & DIA & $174>104$ & Atrazine D5 & $80(13)$ & 32 & 59 & 515 \\
\hline 7 & Irgarol 1051 & $254>198$ & Atrazine D5 & $112(9)$ & 1 & 60 & 544 \\
\hline 8 & Prometryn & $242>158$ & Atrazine D5 & $98(11)$ & 1 & 62 & 641 \\
\hline 9 & Propazine & $230>146$ & Atrazine D5 & $105(15)$ & 3 & 48 & 446 \\
\hline 10 & Simazine & $202>132$ & Atrazine D5 & 78 (13) & 9 & 53 & 625 \\
\hline 11 & Terbuthylazine & $230>174$ & Atrazine D5 & $103(13)$ & 3 & 49 & 488 \\
\hline 12 & Terbutryn & $242>186$ & Atrazine D5 & $110(8)$ & 1 & 50 & 545 \\
\hline 13 & Chlortoluron & $213>72$ & Diuron D6 (239>78) & $80(11)$ & 9 & 53 & 632 \\
\hline 14 & Diuron & $233>72$ & Diuron D6 & $80(14)$ & 15 & 53 & 602 \\
\hline 15 & DCPMU & $219>127$ & Diuron D6 & $102(8)$ & 49 & 43 & 450 \\
\hline 16 & DCPU & $205>127$ & Diuron D6 & $122(16)$ & 46 & 39 & 397 \\
\hline 17 & Fenuron & $165>72$ & Diuron D6 & $75(10)$ & 8 & 49 & 520 \\
\hline 18 & Isoproturon & $207>72$ & Diuron D6 & $82(8)$ & 5 & 66 & 477 \\
\hline 19 & IPPMU & $193>94$ & Diuron D6 & $85(12)$ & 19 & 52 & 544 \\
\hline 20 & IPPU & $179>137$ & Diuron D6 & $99(12)$ & 43 & 49 & 393 \\
\hline 21 & Linuron & $249>160$ & Diuron D6 & $88(10)$ & 54 & 42 & 520 \\
\hline 22 & Metobromuron & $259>170$ & Diuron D6 & $75(11)$ & 59 & 61 & 639 \\
\hline 23 & Metoxuron & $229>72$ & Diuron D6 & $87(11)$ & 8 & 54 & 552 \\
\hline 24 & Monolinuron & $215>126$ & Diuron D6 & $92(6)$ & 38 & 60 & 487 \\
\hline 25 & Monuron & $199>72$ & Diuron D6 & $85(11)$ & 25 & 57 & 555 \\
\hline 26 & Neburon & $275>88$ & Diuron D6 & $107(18)$ & 44 & 45 & 483 \\
\hline 27 & Acetochlor & $270>224$ & Metolachlor D6 (290>258) & 91 (17) & 53 & 52 & 454 \\
\hline 28 & Alachlor & $270>238$ & Metolachlor D6 & $97(14)$ & 54 & 44 & 526 \\
\hline 29 & Metolachlor & $284>252$ & Metolachlor D6 & $95(18)$ & 15 & 50 & 525 \\
\hline 30 & Metazachlor & $278>134$ & Metolachlor D6 & $73(13)$ & 13 & 70 & 606 \\
\hline
\end{tabular}


$421{ }^{\mathrm{c}}$ Concentrations calculated with the solid phase extractions of $200 \mathrm{~mL}$ of river water spiked with the test 422 chemicals. Quantifications were carried out with internal standardizations.

423

424

425

426

427 


\section{FIGURES}

429

430

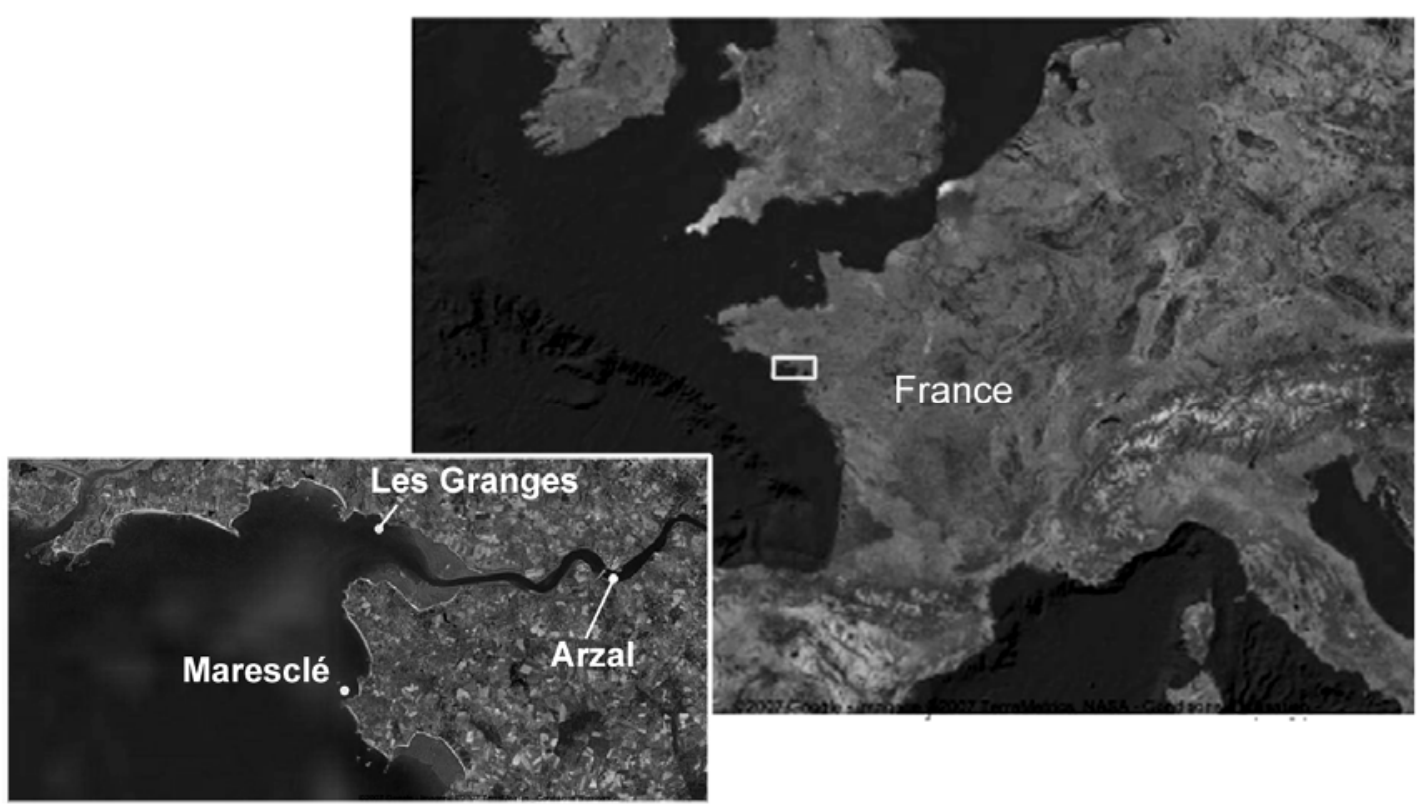

431

432 Figure 1. Location of the Vilaine estuary (Brittany, France) and the 3 sampling sites (Arzal 433 dam, Les Granges and Maresclé).

434 


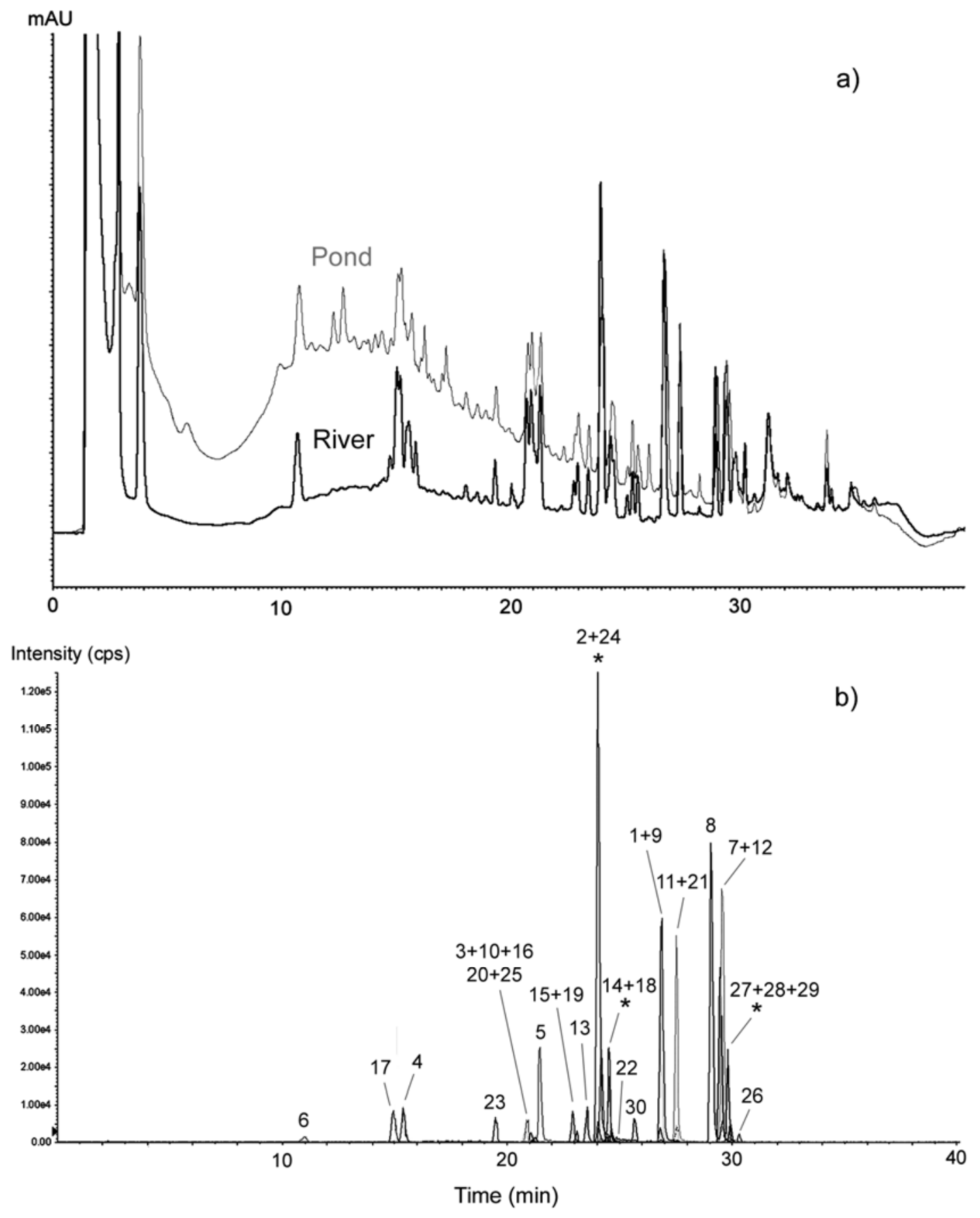

437 Figure 2. (a) HPLC-DAD $(\lambda=220 \mathrm{~nm})$ analysis of a $50 \mu \mathrm{g} \mathrm{L}^{-1}$ standard mixture in either pond or 438 river matrix. (b) HPLC-ESI-MS/MS analysis of a $10 \mu \mathrm{g} \mathrm{L}^{-1}$ standard mixture in HPLC grade 439 acetonitrile:water (20:80, v/v) mixture. Peak number attributions are reported in Table 4. $\left({ }^{*}\right)$ 440 Internal standards: atrazine D5, diuron D6 and metolachlor D6. 


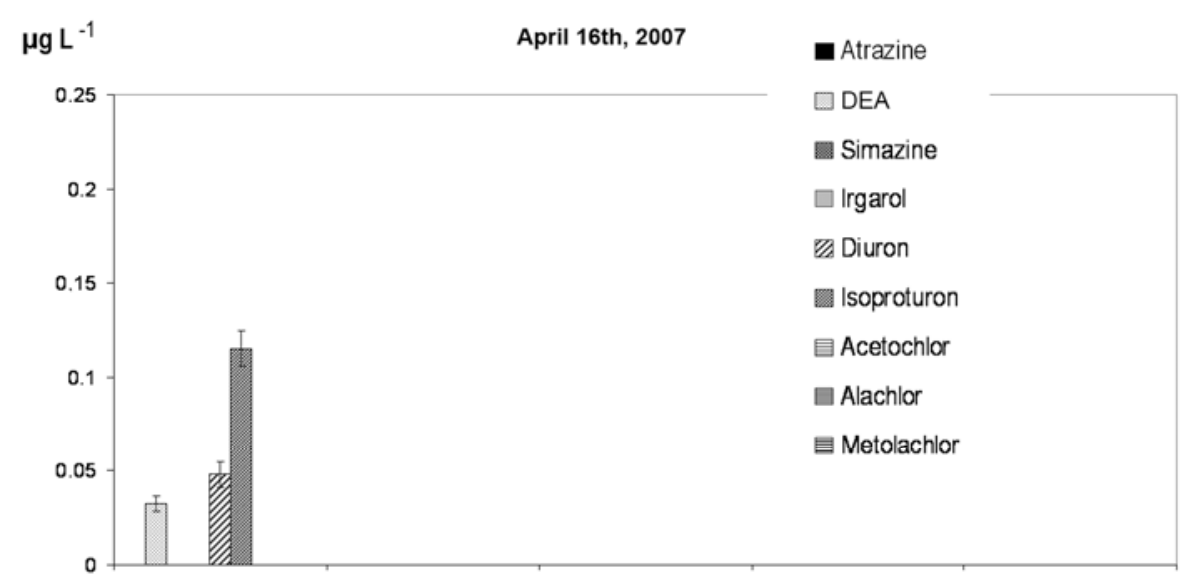

May 29th, 2007

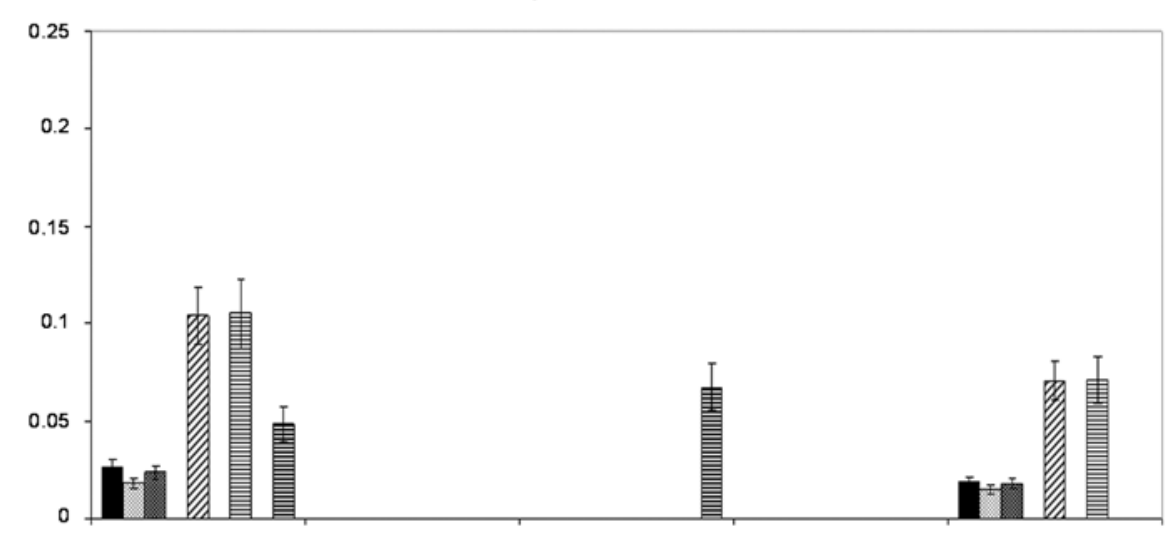

June 12th, 2007

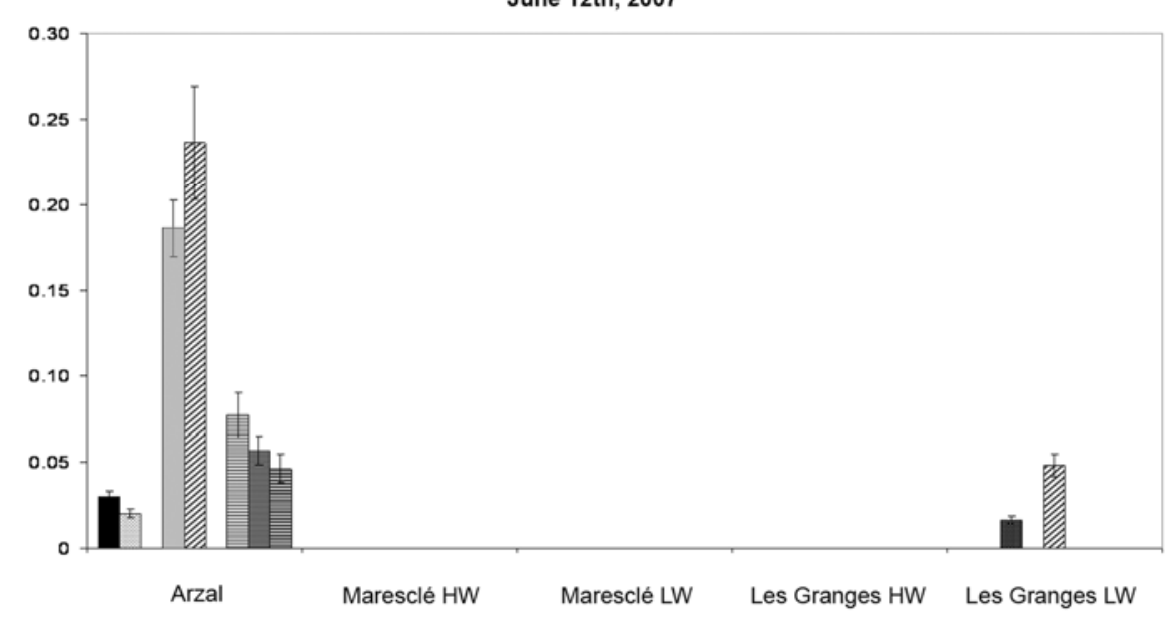

444 Figure 3. Concentrations ( $\mu \mathrm{g} \mathrm{L}^{-1}$ ) of the different herbicides in the water samples from the 445 Arzal dam and the Vilaine estuary (Les Granges and Maresclé). The samples were collected at 446 either low (LW) or high water (HW). 
448 
450 1. D. Barceló and M.-C. Hennion, Trace determination of pesticides and their degradation $451 \quad$ products in water, Elsevier, Amsterdam, 1997.

452 2. Directive 2000/60/EC of the European Parliament and of the Council of 23 October 4532000 establishing a framework for Community action in the field of water policy, OJ L

3. COD/2006/0129, Water policy: establishment of environmental quality standards EQS (amend. Directive 2000/60/EC) 2006.

4. Council Directive 98/83/EC of 3 November 1998 on the quality of water intended for human consumption, OJ L 330, 5.12.1998, 32-54.

5. H. Jiang, C. D. Adams and W. Koffskey, J. Chromatogr. A, 2005, 1064, 219-226.

6. D. A. Devault, G. Merlina, P. Lim, J.-L. Probst and E. Pinelli, J. Environ. Monit., 2007, 9, 1009-1017.

7. T. Dagnac, S. Bristeau, R. Jeannot, C. Mouvet and N. Baran, J. Chromatogr. A, 2005, 1067, 225-233.

8. R. Carabias-Martínez, C. García-Hermida, E. Rodríguez-Gonzalo, F. E. Soriano-Bravo and J. Hernández-Méndez, J. Chromatogr. A, 2003, 1002, 1-12.

9. $\quad$ S. Dupas, P. Scribe and J.-F. Dubernet, J. Chromatogr. A, 1996, 737, 117-126

10. K. A. Hostetler and E. M. Thurman, Sci. Total Environ., 2000, 248, 147-155.

11. R. Carabias-Martinez, E. Rodriguez-Gonzalo, E. Herrero-Hernandez and J. HernandezMendez, Anal. Chim. Acta, 2004, 517, 71-79.

12. R. Carabias-Martinez, E. Rodriguez-Gonzalo and E. Herrero-Hernandez, J. Chromatogr. A, 2005, 1085, 199-206.

13. E. Ayano, H. Kanazawa, M. Ando and T. Nishimura, Anal. Chim. Acta, 2004, 507, 215222.

14. I. Losito, A. Amorisco, T. Carbonara, S. Lofiego and F. Palmisano, Anal. Chim. Acta, 2006, 575, 89-96.

15. J. M. F. Nogueira, T. Sandra and P. Sandra, Analytica Chimica Acta, 2004, 505, 209215.

16. J. Zrostlikova, J. Hajslova, J. Poustka and P. Begany, J. Chromatogr. A, 2002, 973, 1326.

17. R. Bossi, K. V. Vejrup, B. B. Mogensen and W. A. H. Asman, J. Chromatogr. A, 2002, 957, 27-36.

18. L. Gomides Freitas, C. W. Götz, M. Ruff, H. P. Singer and S. R. Müller, J. Chromatogr. A, 2004, 1028, 277-286.

19. L. Comoretto and S. Chiron, Sci.Total Environ., 2005, 349, 201-210.

20. A. Borba da Cunha, M. López de Alda, D. Barceló, T. Pizzolato and J. dos Santos, Anal. Bioanal. Chem., 2004, 378, 940-954.

21. T. Reemtsma, Trends Anal.Chem., 2001, 20, 533-542.

22. R. E. Ardrey, Liquid Chromatography-Mass Spectrometry: An Introduction (Analytical Techniques in the Sciences), John Wiley \& Sons, Chichester, 2003.

23. N. Mazzella, J.-F. Dubernet and F. Delmas, J. Chromatogr. A, 2007, 1154, 42-51.

24. P. J. Taylor, Clinical Biochemistry, 2005, 38, 328-334

25. ISO 8245:1999 - Water quality - Guidelines for the determination of total organic carbon (TOC) and dissolved organic carbon (DOC), 1999.

26. T. L. Constantopoulos, G. S. Jackson and C. G. Enke, J. Am. Soc. Mass Spectrom., 1999, 10, 625-634.

27. M. Stüber and T. Reemtsma, Anal. Bioanal. Chem., 2004, 378, 910-916. 
28. R. J. C. A. Steen, A. C. Hogenboom, P. E. G. Leonards, R. A. L. Peerboom, W. P. Cofino and U. A. T. Brinkman, J. Chromatogr. A, 1999, 857, 157-166.

29. M. D. Gil-García, D. Barranco-Martínez, M. Martínez-Galera and P. Parrilla-Vázquez, Rapid Commun. Mass Spectrom., 2006, 20, 2395-2403.

30. C. Harman, O. Bøyum, K. E. Tollefsen, K. Thomas and M. Grung, J. Environ. Monit., 2008, 10, 239-247.

31. H. Okamura, T. Watanabe, I. Aoyama and M. Hasobe, Chemosphere, 2002, 46, 945951.

32. S. D. W. Comber, M. J. Gardner and A. B. A. Boxall, J. Environ. Monit., 2002, 4, 417425.

33. 2000/60/EC, Directive 2000/60/EC of the European Parliament and of the Council of 23 October 2000 establishing a framework for Community action in the field of water policy, OJ L 327, 22.12.2000, 1-73.

34. D. A. Alvarez, J. D. Petty, J. N. Huckins, T. L. Jones-Lepp, D. T. Getting, J. P. Goddard and S. E. Manahan, Environ. Toxicol. Chem., 2004, 23, 1640-1648. 